\title{
Revision of the taxonomic status of two coelotine species (Araneae: Agelenidae) from Japan
}

\author{
Ken-ichi Okumura ${ }^{1 *}$, Naoki Koike ${ }^{2} \&$ Takafumi Nakano ${ }^{3}$ \\ ${ }^{1}$ Nagasaki Prefectural Nagasaki Kakuyo Senior High School, Sueishi-machi, 157-1, Nagasaki-shi, Nagasaki, 850-0991, Japan \\ E-mail: coelotes@hor.bbiq.jp \\ ${ }^{2}$ Minamichitose-machi, 982, Nagano-shi, Nagano, 380-0822, Japan \\ ${ }^{3}$ Graduate School of Education, Hiroshima University, Kagamiyama, 1-1-1 Higashihiroshima-shi, Hiroshima, 739-8524, Japan \\ *Corresponding author
}

\begin{abstract}
Taxonomic accounts of two species belonging to the subfamily Coelotinae from Japan are reviewed. Iwogumoa portus Nishikawa 2009 originally described from Osaka, Japan and Coelotes plancyi Simon 1880 described from Beijing, China are considered to be conspecific. Therefore the former is synonymized with the latter, and C. plancyi is transferred to the genus Iwogumoa Kishida 1955. Coelotes inabaensis Arita 1974 described from Tottori, Japan is placed under the genus Dichodactylus Okumura 2017.
\end{abstract}

Key words - Coelotinae, taxonomy, new synonymy, new combination, COI

\section{Introduction}

One hundred and seventeen species of the subfamily Coelotinae have been recorded in Japan to date (World Spider Catalog 2017). However, most of them have been placed under the genus Coelotes Blackwall 1841, although a phylogenetic study revealed that Coelotes is a polyphyletic taxon (Chen et al. 2016). Therefore, the precise taxonomic status of many Japanese species remains uncertain, and thus should be elucidated by morphological and molecular studies.

Coelotes plancyi Simon 1880 was described from Beijing, China, and has been considered to be indigenous to Japan as well (Bösenberg \& Strand 1906; Saito 1941; Zhu \& Zhang 2011). According to the original description (Simon 1880), this species is closely related to Coelotes insidiosus L. Koch 1878 (Iwogumoa insidiosa at present), which is the type species of the genus Iwogumoa Kishida 1955. However, reconsideration of the taxonomic status and proper revision of the genus name have not been made up to the present, and this species is thus still classified under Coelotes. Moreover, exact identification of this species is difficult because the figures by Simon (1880) provided only simple and partial drawings of its male palp. Therefore, this species has been treated as an unidentified species for a long time in Japan. Recently, one Iwogumoa species, I. portus Nishikawa 2009, was described by using the specimens collected from Osaka (type locality), Chiba, Tokyo, and Yamaguchi (Nishikawa 2009). Thus, I. portus shows discontinuous distribution and has been primarily collected from urban areas and near the seaport or airport, hence the species might be an artificially introduced species. Moreover, morphological characteristics of I. portus are almost concordant with those of $C$. plancyi described by recent studies (e.g. Song et al. 2001; Zhu \& Zhang 2011; Wang 2017). Therefore, we evaluate the taxonomic relation of both C. plancyi and I. portus by means of a molecular phylogeny inferred from mitochondrial cytochrome $c$ oxidase subunit I (mt-COI) sequences and morphological examination of the type specimens of I. portus.

The other species, of which taxonomic account is revised in this study, is Coelotes inabaensis Arita 1974 originally described from Tottori, Japan (Arita 1974). By a careful examination of genital organs of both sexes, it became clear that this species has the morphological characteristics of the genus Dichodactylus Okumura 2017. Prior to this, the three Japanese 'Coelotes' species diagnosed by same characteristics are currently placed under Dichodactylus: D. tarumii (Arita 1976) (the type species), D. satoi (Nishikawa 2003), and D. shinshuensis Okumura 2017. Accordingly, we analyze mt-COI data of Dichodactylus specimens to test whether $C$. inabaensis could be treated as a fourth species under this genus.

The present study contributes to our knowledge about the species diversity of the genera Iwogumoa and Dichodactylus in Japan.

\section{Materials and methods}

\section{Sampling and morphological examination}

In total 19 coelotine specimens used for molecular phylogenetic analyses were collected from 17 localities, Japan (see Appendix): those were identified according to 
Okumura et al. (2009), and have been deposited in the Zoological Collection of Kyoto University (KUZ). In addition to these specimens, morphological characteristics of the type specimens of Iwogumoa portus and the newly collected specimens identified with Coelotes inabaensis were examined. A part of the examined specimens of $C$. inabaensis have been deposited in the Tsukuba Collection Center, National Museum of Nature and Science, Tokyo (NSMT). Examination of the specimens was performed using an Olympus SZX-7 stereomicroscope. Photographs were taken using an Olympus E-620 digital camera attached to the microscope.

\section{DNA extraction, polymerase chain reaction and se- quencing}

The third or fourth leg was dissected from the body of each specimen, and preserved in $99.5 \%$ ethanol at $4^{\circ} \mathrm{C}$ for DNA extraction. DNA was extracted from the muscle of the leg. The extraction of genomic DNA followed Okamoto et al. (2006) along with a minimally destructive method by Paquin \& Vink (2009). Partial sequences of mt-COI were used for phylogenetic analysis. Primer sets for PCR and cycle sequencing (CS) reaction for COI were, COIARAF (5'-ACAAATCATAAAGATATTGC-3'; this study) and COIARAR (5'-ATAGCATAAATTATTCCTAA-3'; this study) (PCR and CS). All amplification reactions were performed in a GeneAmp PCR System 2700 (Applied Biosystems Ltd., ABI), or a MyCycler (Bio-Rad Laboratories). The reactions were initially heated to $94^{\circ} \mathrm{C}$ for $5 \mathrm{~min}$, followed by 35 cycles of $94^{\circ} \mathrm{C}(10 \mathrm{sec}), 40^{\circ} \mathrm{C}(20$ sec), and $72^{\circ} \mathrm{C}(42 \mathrm{sec})$, and a final extension at $72^{\circ} \mathrm{C}$ for 6 min. PCR products were checked for the presence of bands and their size by using agarose gel (2\%) electrophoresis, and then the amplified DNA fragments were purified using polyethylene glycol (20\% PEG 6000) precipitation. All samples were sequenced in both directions. Sequencing reactions were performed using a BigDye Terminator v3.1 Cycle Sequencing Kit (ABI). Each sequencing reaction mixture was incubated at $96^{\circ} \mathrm{C}$ for $2 \mathrm{~min}$, followed by 40 cycles of $96^{\circ} \mathrm{C}(10 \mathrm{sec}), 50^{\circ} \mathrm{C}(5 \mathrm{~min})$, and $60^{\circ} \mathrm{C}(42 \mathrm{sec})$. The products were collected by ethanol precipitation and sequenced on an ABI 3130xl Genetic Analyzer (ABI). The obtained sequences were edited using DNA Baser (Heracle Biosoft S.R.L.). The DNA sequences newly obtained in this study have been deposited with the International Nucleotide Sequence Database Collaboration (INSDC) through DNA Data Bank of Japan.

\section{Molecular phylogenetic analyses}

Six specimens classified into five Iwogumoa species were included in the phylogenetic analysis for the taxonomic accounts of I. portus and C. plancyi (see Appendix): I. acco (Nishikawa 1987) (topotype), I. insidiosa, I. interuna (Nishikawa 1977) (topotype), I. nagasakiensis Okumura 2007 (topotype), and I. portus from Nagasaki Prefecture, Japan.
Along with the individual of $C$. inabaensis collected from Tottori Pref., the phylogenetic position of $C$. inabaensis was determined using five specimens of two Dichodactylus species, and seven specimens classified into five Coelotes species morphologically related to Dichodactylus: D. satoi (including topotype), D. tarumii (including topotypes), $C$. kitazawai Yaginuma 1972, C. lamellatus Nishikawa 2009 (topotype), C. musashiensis Nishikawa 1989, C. yahagiensis Nishikawa 2009 (topotype), and C. yodoensis Nishikawa 1977 (topotype).

The previously published mt-COI sequence of $C$. plancyi in the name Asiacoelotes plancyi collected from China was obtained from INSDC (KY778827). The mt-COI sequences were aligned using MEGA 7.0 (Kumar et al. 2016). Maximum likelihood (ML) phylogenies based on $763 \mathrm{bp}$ alignment positions of mt-COI were constructed using MEGA with non-parametric bootstrapping (BS) conducted with 1000 replicates. In the analysis, Tamura-Nei Model was selected for ML analyses using MEGA.

\section{Results and conclusions}

\section{Morphological characteristics}

Iwogumoa portus: Male palp (Fig. 1A, B) has a short conductor with a broad proximal part and thin tip. Cymbial furrow is clearly recognized and the tip protrudes from the lateral side of the cymbium. Patellar apophysis is slender only at the tip. Epigyne (Fig. 1C) has small teeth situated close to each other in anterior part. Spermathecae of female internal genitalia (Fig. 1D) are kidney shaped and widely separated from each other. C. plancyi also has abovementioned characteristics without exception (Song et al. 2001; Zhu \& Zhang 2011; Wang 2017). Therefore we consider that $I$. portus and $C$. planyci should be treated as the conspecific.

Coelotes inabaensis: This species is small-sized, and characterized by the possession of four retromarginal teeth on the chelicera. Male palp (Fig. 2A, B) has two patellar apohyses and no lateral tibial apophysis. Conductor is broad and strongly curved toward the tip of the cymbium. Epigyne (Fig. 2C) is oval-shaped and has no teeth. Female internal genitalia (Fig. 2D) has irregularly convolute and anteroposteriorly elongated spermathecae. Among the above morphological characteristics, having two patellar apophyses and no lateral tibial apophysis in male palp, and irregularly convolute and anteroposteriorly elongated spermathecae in the female internal genitalia can be enumerated as common points of the genus Dichodactylus (Okumura 2017). As mentioned above, morphological characteristics of this species strongly suggested a change in the taxonomic status.

\section{Molecular phylogenetic relationships}

The ML tree (ln $L=-1285.647$; Fig. 3) for estimating the phylogenetic positions of $I$. portus and $C$. plancyi showed that these species formed a monophyletic lineage $(\mathrm{BS}=100 \%)$. The monophyly of three Iwogumoa species, 


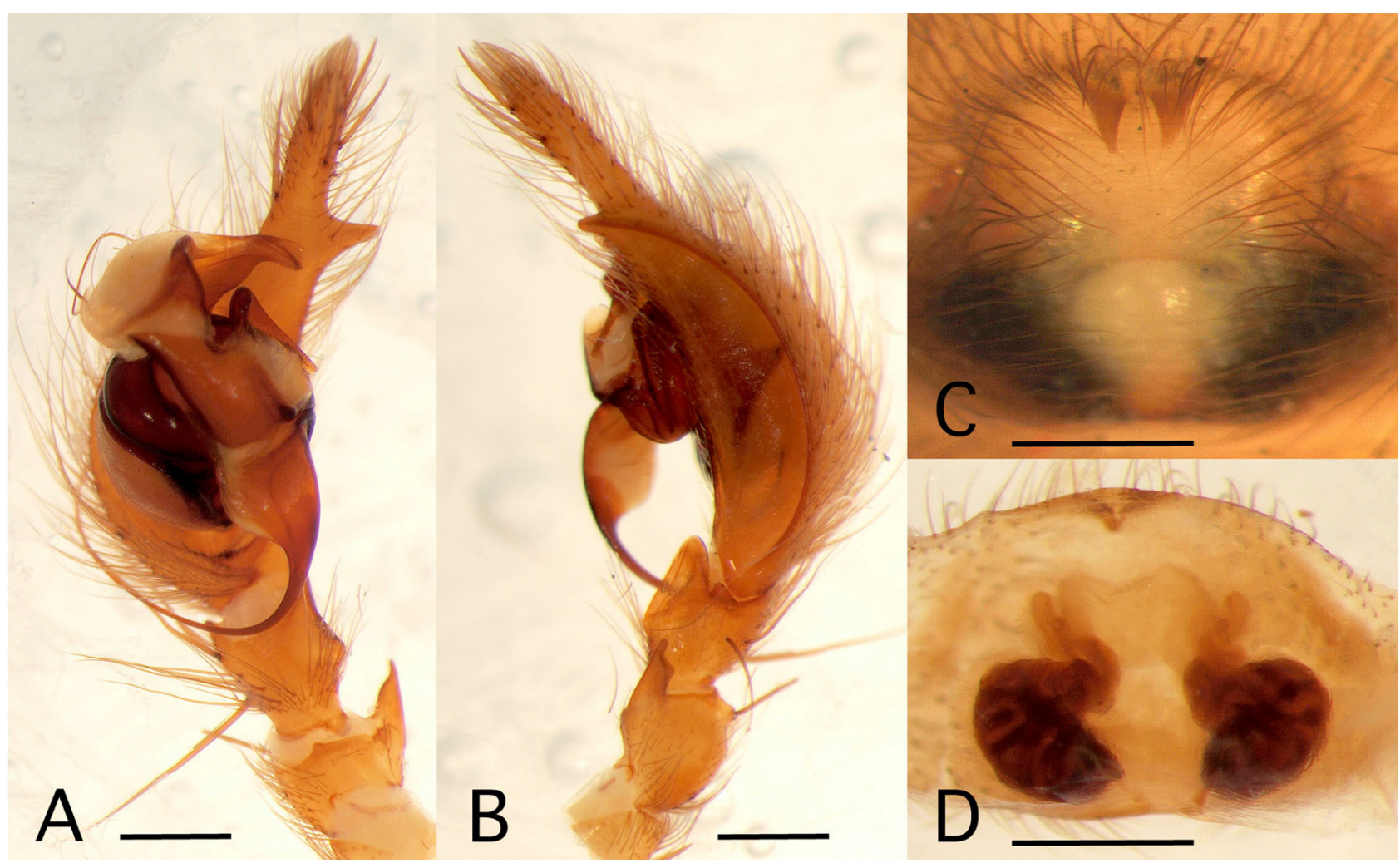

Fig. 1. Iwogumoa plancyi (Simon 1880). Holotype (A-B), allotype (C) and paratype (D) of Iwogumoa portus Nishikawa 2009. A, left male palp, ventral view; B, same, retrorateral view; C, epigyne, ventral view; D, internal female genitalia, dorsal view. Scales $=0.5 \mathrm{~mm}$.
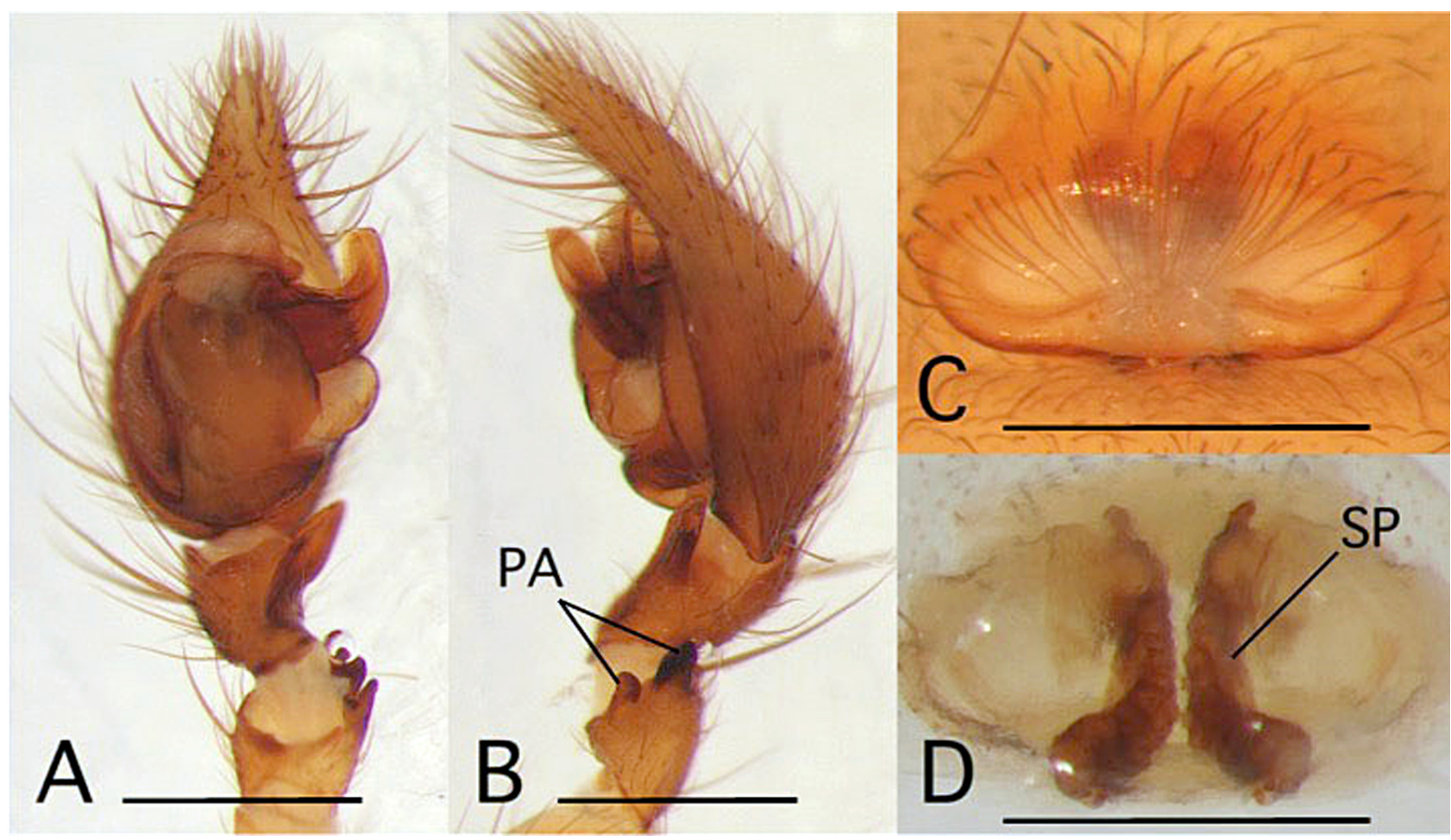

Fig. 2. Dichodactylus inabaensis (Arita 1974). Mt. Kenashi, Shinjo Village, Maniwa County Okayama Pref. (A-B), and Wakasugi Pass, Nishiawakura Village, Aida County, Okayama Pref. (C-D). A, left male palp, ventral view; B, same, retrorateral view; C, epigyne, ventral view; D, internal female genitalia, dorsal view. Scales $=0.5 \mathrm{~mm}$. 


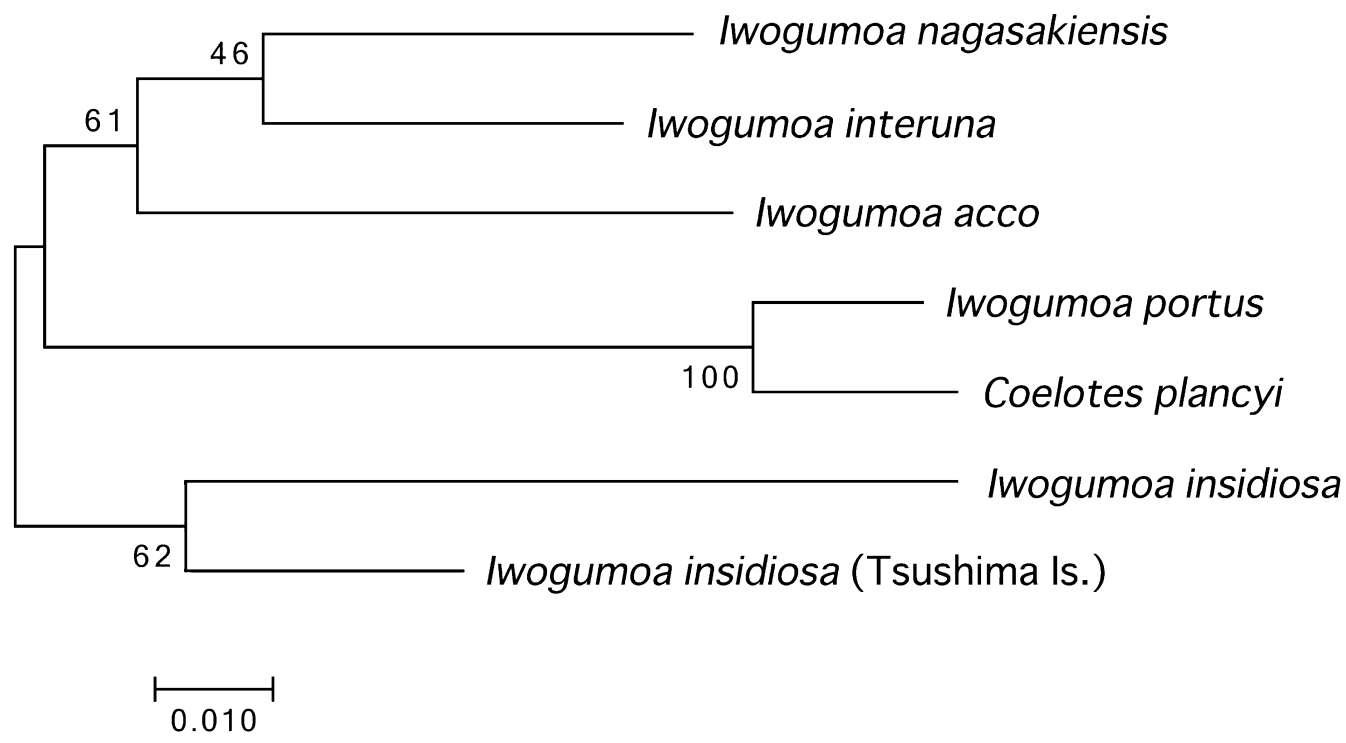

Fig. 3. Maximum likelihood tree for $763 \mathrm{bp}$ alignment positions of mt-COI marker of the genus Iwogumoa collected from Japan and Coelotes plancyi from China. Numbers on nodes indicating bootstrap values.

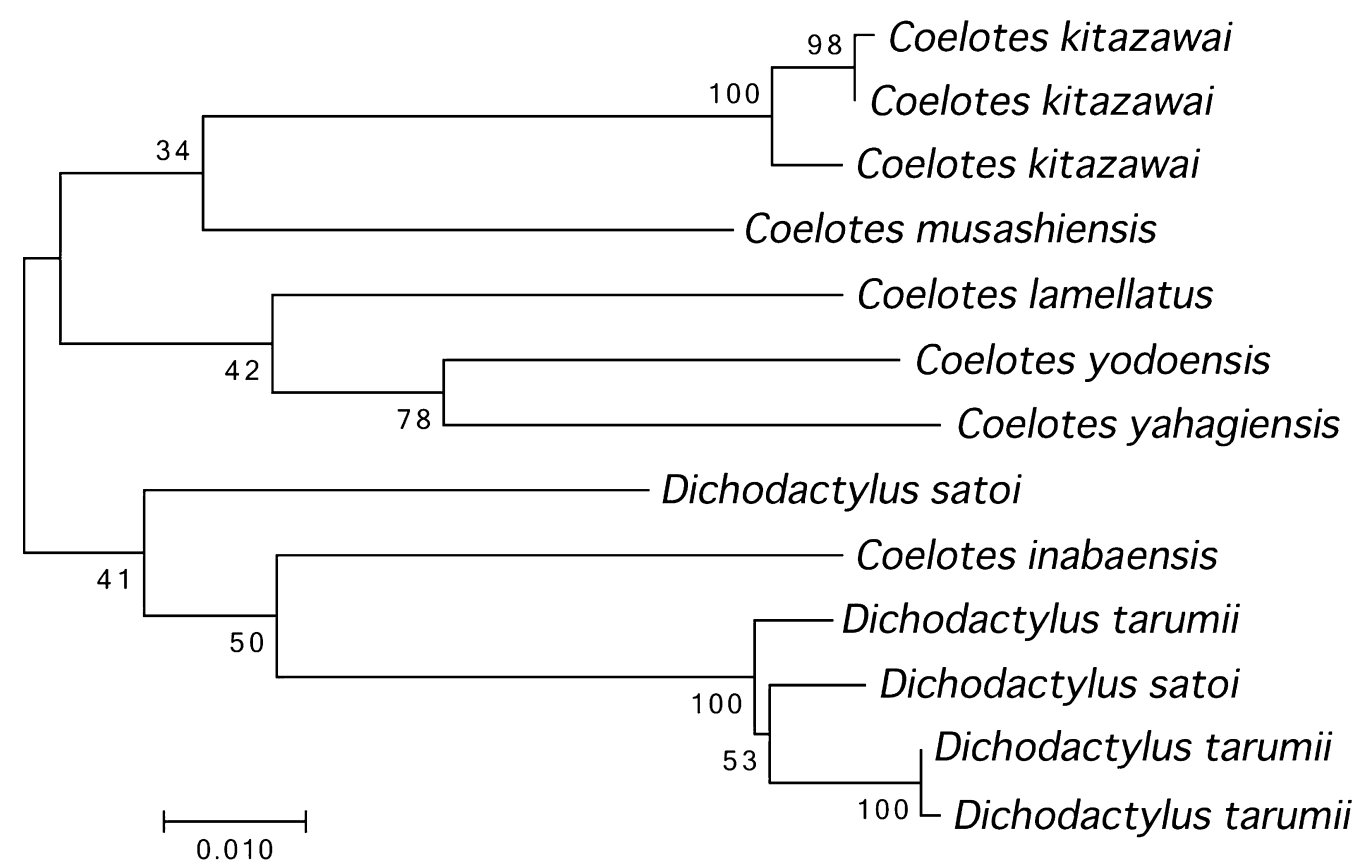

Fig. 4. Maximum-likelihood tree for 763 bp alignment positions of mt-COI marker of the genus Dichodactylus and small sized Coelotes species from Japan. Numbers on nodes indicating bootstrap values.

namely I. acco, I. interuna and I. nagasakiensis, was weakly supported (BS=61\%). Two specimens of I. insidiosa different in collection locality formed a monophyletic lineage with the slight support value $(\mathrm{BS}=62 \%)$. The obtained phylogenetic relationship between $I$. portus and $C$. plancyi supported the results of the morphological analysis of the two species, and also suggested that $C$. plancyi belongs to the genus Iwogumoa.

The obtained ML tree ( $\ln L=-2279.490$; Fig. 4) for estimating the phylogenetic position of $C$. inabaensis failed to recover the monophyly of Dichodactylus $(\mathrm{BS}=41 \%)$.
The sample identified as D. satoi collected from Mt. Ibuki, Gifu Prefecture, Japan was nested within the clade comprised D. tarumii samples $(\mathrm{BS}=100 \%)$. Although the support value was not high $(\mathrm{BS}=50 \%), C$. inabaensis formed a monophyletic lineage with $D$. tarumii clade. According to the obtained phylogenetic characteristics, $C$. inabaensis can be treated as the fourth Dichodactylus species. The present mt-COI data obtained from the other small sized 'Coelotes' species will help elucidating their taxonomic status by a future study. 


\section{Taxonomic conclusions}

\section{Iwogumoa plancyi (Simon 1880) comb. nov.} (Fig. 1)

Coelotes plancyi Simon 1880, pp. 115-116, pl. 3, figs. 12-14; Song \& Hubert 1983, p. 4, figs. 6-9; Song 1987, p. 194, fig. 152; Song et al. 1999, p. 377, fig. 223; Hu 2001, p. 143, fig. 53; Song, Zhu \& Chen 2001, p. 293, fig. 186; Zhu \& Zhang 2011, pp. 318-319, fig. 230.

Coras plancyi: Simon 1898, p. 258; Bösenberg \& Strand 1906, p. 301; Saito 1941. pp. 50-51.

Coelotes insidiosus: Lehtinen 1967, p. 224. (Rejected syn.)

Iwogumoa portus Nishikawa 2009, p. 70, figs. 111-116; Okumura et al. 2009, p. 199, figs. 2-2-33-393-398. syn. nov.

Specimens examined. One male (holotype of I. portus; NSMT), Nippon-bashi, Naniwa-Ku, Osaka City, Osaka Prefecture, October 19, 1975, Y. Watanabe leg.; 2 females (allotype and paratype of I. portus; NSMT), Kôsei, Minato$\mathrm{Ku}$, Osaka City, Osaka Prefecture, January 6, 1973, H. Shirakawa leg.

Remarks. Judging from the distributional areas in Japan, the Japanese populations of this species are likely to be naturalized from China. The demographic history of the Japanese I. plancyi should be revealed on the basis of additional genetic data obtained from the sufficient specimens of the species.

\section{Dichodactylus inabaensis (Arita 1974) comb. nov.} (Fig. 2)

Coelotes inabaensis Arita 1974, pp. 41-43, figs. 1-5; Nishikawa 1974, p. 176, figs. 12-14; Nishikawa 1976, p. 1060; Yaginuma 1986, p. 149, fig. 81; Okumura et al. 2009, p. 197, figs. 2-2-33-346-348.

Specimens examined. All the specimens were collected from Okayama Pref., Japan by K. Nojima leg. Takiyama, Nagi Town, Katsuta County, 1 male and 1 female, October 22, 1989; Wakasugi Pass, Nishiawakura Village, Aida County, 1 male and 1 female, November 12, 1989, 1 female, June 2, 1990; Hiruzen-shitao, Maniwa City, 2 males and 3 females, October 29, 1990; Kurami, Kamo Town, Tsuyama City, 2 males and 1 female, November 3, 1990, 1 male, May 28, 1991; Mt. Kenashi, Shinjo Village, Maniwa County, 2 males and 2 females, November 15, 1993; Higashiaono, Mimasaka City, 1 male, October 1, 2000. Two samples used for taking the photographs are deposited in NSMT.

Diagnosis. Dichodactylus inabaensis can be distinguished from the other congener by the following points. Male palp (Fig. 2A-B); conductor is broad and anteriorly bent, but that of the others is thin (D. tarumii and $D$. shinshuensis), or ventrally bent (D. satoi). Female genitalia (Fig. 2C-D): epigyne is oval-shaped and without epigynal teeth, but that of the others is hourglass shaped (D. tarumii and D. shinshuensis), or hexagonal shaped (D. satoi). In addition, D. tarumii has epigynal teeth.

\section{Acknowledgments}

The authors express their thanks to Dr Yoh Ihara, Tatsumi Suguro and Kouichi Nojima for providing valuable coelotine specimens.

\section{References}

Arita, T. 1974. A new species of Coelotes (Araneae: Agelenide) from Tottori Prefecture, Japan. Acta Arachnol., 25: 41-43.

Bösenberg, W. \& Strand, E. 1906. Japanische Spinnen. Abh. Senckenb. Naturf. Ges., 30: 93-422, pls. 3-10.

Chen, L., Zhao, Z. \& Li, S. 2016. Sinocoelotes gen. n., a new genus of the subfamily Coelotinae (Araneae, Agelenidae) from Southeast Asia. ZooKeys, 614: 51-86.

Hu, J. L. 2001. Spiders in Qinghai-Tibet Plateau of China. Henan Sci. Technol. Publ. House, Zhengzhou, 658 pp.

Kumar, S. Stecher, G. \& Tamura, K. 2016. MEGA7: Molecular Evolutionary Genetics Analysis version 7.0 for bigger datasets. Mol. Biol. Evol., 33: 1870-1874.

Lehtinen, P. T. 1967. Classification of the Cribellate spiders and some allied families, with notes on the evolution of the suborder Araneomorpha. Ann. Zool. Fenn., 4: 199-468.

Nishikawa, Y. 1974. Japanese spiders of the genus Coelotes (Araneae: Agelenidae). Fac. Let. Rev. Otemon Gakuin Univ. 8: 173-182. (In Japanese)

Nishikawa, Y. 1976. A preliminary note on the geographical distribution of the genus Coelotes in Japan (Araneae: Agelenidae). Ess. Stud. Commem. 10th Anniv. Otemon Gakuin Univ. (Fac. Let.), pp. 1043-1066. (In Japanese)

Nishikawa, Y. 2009. A new genus and 44 new species of the Family Coelotidae (Arachnida, Araneae) from Japan. Pp. 51-70. In: Ono, H. (ed.) The Spiders of Japan. Tokai Univ. Press, Kanagawa, xvi + $739 \mathrm{pp}$.

Okamoto, T., Motokawa, J., Toda, M. \& Hikida, T. 2006. Parapatric distribution of the lizards Plestiodon (formerly Eumeces) latiscutatus and P. japonicus (Reptilia: Scinidae) around the Izu Peninsula, central Japan, and its biogeographic implications. Zool. Sci., 23: 419-425.

Okumura, K. 2017. Dichodactylus gen. nov. (Araneae: Agelenidae: Coelotinae) from Japan. Species Diversity, 22: 29-36.

Okumura, K., Nishikawa, Y., Shimojana, M. \& Ono, H. 2009. Coelotidae. Pp. 174-205. In: Ono, H. (ed.) The Spiders of Japan. Tokai Univ. Press, Kanagawa, xvi +739 pp. (In Japanese)

Paquin, P. \& Vink, C. J. 2009. Testing compatibility between molecular and morphological techniques for arthropod systematics: a minimally destructive DNA extraction method that preserves morphological integrity, and the effect of lactic acid on DNA quality. J. Insect Conserv., 13: 453-457.

Saito, S. 1941. Suborder arachnomorphae, tetrasticta, trionycha I. Fauna nipponica. Sanseido, Tokyo, 220 pp. (In Japanese)

Simon, E. 1880. Etudes arachnologiques. 11e Mémoire. XVII. Arachnides recueilles aux environs de Pékin par M. V. Collin de Plancy. Ann. Soc. Entomol. France Ser. 5, 10: 97-128.

Simon, E. 1898. Histoire naturelle des araignées. Encyclopédie Roret, Paris, 2: 193-380.

Song, D. X. 1987. Spiders from agricultural regions of China (Arachnida: Araneae). Agr. Publ. House, Beijing, 376 pp.

Song, D. X. \& Huber, M. 1983. A redescription of the spiders of Beijing described by E. Simon in 1880. J. Huizhou Teach. Coll. 1983: $1-23$.

Song, D. X., Zhu, M. S. \& Chen, J. 1999. The Spiders of China. Hebei Univ. Sci. Techol. Publ. House, Shijiazhuang, 640 pp.

Song, D. X., Zhu, M. S. \& Chen, J. 2001. The Fauna of Hebei, China: Araneae. Hebei Univ. Sci. Techol. Publ. House, 
Shijiazhuang, $510 \mathrm{pp}$.

Wang, X. P. 2017. Online Coelotinae, online at http://www. amaurobiidae.com, version 2.0, accessed on 8 July 2017.

World Spider Catalog 2017. World Spider Catalog. Natural History Museum Bern, online at http://wsc.nmbe.ch, version 18.0, accessed on 25 June 2017.
Yaginuma, T. 1986. Spiders of Japan in Colour, New Eddition. Hoikusha, Osaka, 350 pp., 64 pls. (In Japanese)

Zhu, M. S. \& Zhang, B. S. 2011. Spider Fauna of Henan: Arachnida: Araneae. Science Press, Beijing, xxii +558 pp.

Received July 13, 2017 / Accepted September 6, 2017

Appendix. Samples with collection localities and INSDC accession numbers used for molecular phylogenetic analyses.

\begin{tabular}{|c|c|c|c|c|}
\hline Species & Sex & Voucher & Collection localities & Accession No. \\
\hline Coelotes kitazawai & Female & KUZ Z1889 & Urabandai, Kitashiobara Village, Yama County, Fukushima Pref. & LC310804 \\
\hline Coelotes kitazawai & Male & KUZ Z1890 & Ryusen-sindo cave, Iwaizumi, Iwaizumi Town, Simohei County, Iwate Pref. & LC310805 \\
\hline Coelotes kitazawai & Male & KUZ Z1891 & Hiyamizu Pass, Okunai-Tsukushimori, Mutsu City, Aomori Pref. & LC310806 \\
\hline Coelotes lamellatus & Male & KUZ Z1894 & Occhi, Ueno Village, Tano County, Gunma Pref. & LC310807 \\
\hline Coelotes musashiensis & Female & KUZ Z1905 & Hirasawa, Suruga Ward, Shizuoka City, Shizuoka Pref. & LC310808 \\
\hline Coelotes yahagiensis & Female & KUZ Z1904 & Mt. Sangane $260 \mathrm{~m}$ alt. Higashi-hazu Town, Nishio City, Aichi Pref. & LC310809 \\
\hline Coelotes yodoensis & Female & KUZ Z1902 & Minoo park, Minoo City, Osaka Pref. & LC310810 \\
\hline Dichodactylus inabaensis & Female & KUZ Z1899 & Ashizu Valley, Chizu Town, Yazu County, Tottori Pref. & LC310811 \\
\hline Dichodactylus satoi & Male & KUZ Z1893 & Mt. Ena, Nakatsugawa City, Gifu Pref. & LC310812 \\
\hline Dichodactylus satoi & Female & KUZ Z1892 & Mt. Ibuki, Ibigawa Town, Ibi County, Gifu Pref. & LC310813 \\
\hline Dichodactylus tarumii & Female & KUZ Z1896 & Iwato-ji Temple, Kunisaki City, Oita Pref. & LC310814 \\
\hline Dichodactylus tarumii & Female & KUZ Z1900 & Mt. Daisen, Daisen Town, Saihaku County, Tottori Pref. & LC310815 \\
\hline Dichodactylus tarumii & Female & KUZ Z1901 & Toyofusa, Daisen Town, Saihaku County, Tottori Pref. & LC310816 \\
\hline Iwogumoa acco & Female & KUZ Z1906 & Kōmori-ana cave, Utobara, Futtsu City, Chiba Pref. & LC310817 \\
\hline Iwogumoa insidiosa & Female & KUZ Z1895 & Takazawa, Kuma Village, Kuma County, Kumamoto Pref. & LC310818 \\
\hline Iwogumoa insidiosa & Female & KUZ Z1907 & Mt. Osakadanyama, Izuhara Town, Tsushima City, Nagasaki Pref. & LC310819 \\
\hline Iwogumoa interuna & Female & KUZ Z1903 & Minoo park, Minoo City, Osaka Pref. & LC310820 \\
\hline Iwogumoa nagasakiensis & Female & KUZ Z1897 & Mt. Yasuman $500 \mathrm{~m}$ alt., Hirado City, Nagasaki Pref. & LC310821 \\
\hline Iwogumoa portus & Male & KUZ Z1898 & Ishida Town, Iki City, Nagasaki Pref. & LC310822 \\
\hline
\end{tabular}

